\title{
Effects of interest and relatedness on estimated duration of verbal material
}

\author{
M. F. HAWKINS and W. H. TEDFORD, JR. \\ Southern Methodist University, Dallas, Texas 75275
}

\begin{abstract}
Two 1-min selections of English prose were recorded, differing on the dimension of interest to the listener. They were re-recorded with the words in random order, so as to differ from the first tapes on the dimension of relatedness. Each tape was heard by 20 volunteer undergraduates who estimated the duration of the selection. Interesting tapes were judged significantly shorter $(p<.05)$ than uninteresting ones, and unrelated tapes were judged slightly $(p<.10)$ shorter than related ones. This contradicts a storage size theory of duration, since the related tapes should have been easier to code.
\end{abstract}

Employing a "storage size" metaphor, Robert Ornstein (1975) has developed a theory to explain perceived time duration. Briefly, the theory states that the experience of duration is directly related to the amount of material stored in memory. An increase in storage size increases duration experience, while a reduction in storage size decreases it. The degree of relationship among the items in storage is an important factor in determining the amount of storage size required. Items which are related to each other require less storage space than unrelated items and should produce a shorter duration experience. Ornstein hypothesizes, therefore, that interesting events seem to occupy a short space of time as a result of the establishment of relationships among items which comprise them. However, it seemed to the present authors that "interest" and "relatedness" are separate variables. The present study attempted to manipulate these variables and assess their effect on the experience of duration.

\section{METHOD}

\section{Subjects}

Students in undergraduate psychology classes volunteered to participate in the study. Subjects were tested in four groups of 20 each.

\section{Apparatus}

Four tape recordings of continuous discourse were made which varied on two dimensions: interest and relatedness. The recordings were of passages from two books; one passage was assumed to be interesting to the typical college student, the other uninteresting. The interesting selection was drawn from a novel by Henry Miller (1965) and contained graphic sexual material. The uninteresting passage, excerpted from a current neurology textbook, described the anatomy and physiology of cranial nerves.

Related tapes were recordings of the passages as they appeared in print. Unrelated tapes were made by numbering the words and then selecting their order from a random number table so that the syntax was disrupted. It was assumed that the high percentage of four-letter words would maintain interest even with the disrupted syntax.

The resulting four types of tapes were as follows: interesting related (IR), interesting unrelated (IR), uninteresting related

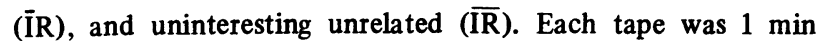
long. A 1-min control tape was made of the alarm of an electric clock.

\section{Procedure}

Before testing, subjects were informed that they were to listen to two tape recordings and to complete a questionnaire afterward. Each group listened to the control tape first, followed by one of the four experimental tapes. A questionnaire was then distributed which asked the subject to rate each of the two tapes on a 7-point scale from "very interesting" to "very uninteresting" and to judge the duration of the experimental tape. The duration of the control tape was represented by a line $7.2 \mathrm{~cm}$ long. Subjects were instructed to draw a line which represented the duration of the experimental tape compared to the control.

\section{RESULTS}

A $t$ test revealed that $I$ tapes were rated as more interesting than $\overline{\mathrm{I}}$ tapes $(\mathrm{t}=9.18, \mathrm{df}=78, \mathrm{p}<.001)$. No difference was found in interest between $R$ and $\bar{R}$ tapes $(\mathrm{t}=.39, \mathrm{df}=78, \mathrm{p}>.25)$.

The mean duration (represented by line length in centimeters) of each of the four tapes was as follows: $\mathrm{IR}=6.3, \overline{\mathrm{I}} \mathrm{R}=7.0, \mathrm{I} \overline{\mathrm{R}}=5.7, \overline{\mathrm{IR}}=6.5$. The $\mathrm{I}$ tapes were subjectively shorter in duration than the $\overline{\mathrm{I}}$ tapes $(F=4.25, \mathrm{df}=1 / 76, \mathrm{p}<.05)$. There was a tendency for $\bar{R}$ tape durations to be judged shorter than $R$ tapes which did not reach significance $(F=2.80, \mathrm{df}=1 / 76$, $\mathrm{p}<.10)$. The $\mathrm{F}$ value of the interaction term was $<1$.

When the six possible pairwise comparisons were made, two were significant at the .05 level. The I $\bar{R}$ tape was judged shorter in duration than the $\overline{I R}$ tape or the İR.

\section{DISCUSSION}

While Ornstein's theory of time perception predicts that related items should be judged as shorter in duration than unrelated items, results of the present study do not support such a prediction. In fact, the trend, though statistically not significant, was in the opposite direction.

Ornstein also hypothesizes that an interesting event seems to have a short subjective duration as a result of the establishment of relationships between the components of the event. 
We found, however, that the $I \bar{R}$ tape had a shorter subjective duration than the IR tape. This demonstrates that unrelated material, which should require more storage space, was judged as shorter in duration than related material, which should require less storage space. Similarly, the duration experience for the $I \bar{R}$ tape was shorter than that for the $\overline{I R}$ tape, despite the fact that both tapes were of unrelated material. It appears that interest is a dimension which varies independently of the degree of relationship.

\section{REFERENCES}

Miller, H. The rosy crucifixion. Evanston, Ill: Greenleaf, 1965. Ornstein. R. E. On the experience of time. New York: Pelican Books, 1975.

(Received for publication June 5, 1976.) 